ISSN: 2528-4002 (media online)

ISSN: 2355-892X (print)

Online: http://e-journal.sari-mutiara.ac.id/index.php/KesehatanMasyarakat

DOI: https://doi.org/10.51544/jkmlh.v6i1.1562

\title{
PENGARUH VARIASI MEDIA DAN JUMLAH TUMBUHAN TYPHA LATIFOLIA TERHADAP PENURUNAN KADAR BOD DAN COD PADA LIMBAH CAIR INDUSTRI TAHU DI SIDOARJO
}

\author{
Lily Oktavia ${ }^{1}$, Mohammad Taufiq ${ }^{1}$, Muchammad Tamyiz ${ }^{1}$ \\ Universitas Nahdlatul Ulama Sidoarjo \\ Email: oktavial800@gmail.com
}

Received: Januari 2021; Accepted: April 2021; Published: Juni 2021

\begin{abstract}
Sidoarjo Regency is one of the supporting districts of East Java province. Sidoarjo Regency is experiencing rapid progress because of the development and potential in trade and industry. One of the industries often found in Sidoarjo Regency is tofu factory. The rapid number of tofu craftsmen industry has caused an increase in the volume of liquid waste which also flows into water bodies. The purpose of this study was to determine the reduction in BOD and COD levels for the tofu factory wastewater treatment in the Sepande area, Sidoarjo Regency using a contructed wetland with Typha latifolia as the remediator. The research stage will be carried out using a laboratory scale using acclimatization as the adaptation stage of Typha latifolia and a crontructed wetland reactor as phytoremediation processing. Based on the results and discussion, it can be concluded that there was a decrease in BOD and COD levels in the tofu industrial wastewater in Sidoarjo using the Constructed Wetland system. The percentage reduction in BOD content was greatest in soil media with 3 stems of Typha latifolia plants and a detention time of 4 days of $72 \%$. While the largest percentage reduction in COD levels was in soil media with 2 stems of Typha latifolia plants and 4 days of detention time of $84 \%$.
\end{abstract}

Keywords: Constructed Wetland, Liquid waste, Typha latifolia

\section{PENDAHULUAN}

Kabupaten Sidoarjo merupakan salah satu kabupaten penyangga provinsi Jawa Timur. Kabupaten Sidoarjo mengalami kemajuan yang pesat karena perkembangan dan potensi perdagangan serta perindustrian. Salah satu industri yang sering dijumpai di Kabupaten Sidoarjo adalah pabrik tahu. Pesatnya jumlah industri pengerajin tahu menyebabkan peningkatan volume limbah cair yang juga mengalir ke badan air. Umumnya pabrik tahu yang ada di Kabupaten Sidoarjo belum memiliki IPAL yang baik akibatnya limbah cair yang langsung dibuang ke badan air tanpa ada pengolahan untuk mencapai ambang batas yang ditetapkan pemerintah.

Limbah cair tahu berasal dari proses 
ISSN: 2528-4002 (media online)

ISSN: 2355-892X (print)

Online: http://e-journal.sari-mutiara.ac.id/index.php/KesehatanMasyarakat

DOI: https://doi.org/10.51544/jkmlh.v6i1.1562

perendaman, pencucian kedelai, penyaringan, penyetakan tahu serta proses pencucian peralatan produksi. Limbah cair yang dihasilkan biasanya kental yang terpisah dari gumpalan tahu. Cairan ini memiliki kadar organik yang tinggi baik BOD maupun COD. Menurut Sugianti (2018), bahan organik pada effluent industri tahu melebihi ambang batas yang ditetap. Selain itu, diketahui limbah cair yang dihasilkan memiliki suhu yang tinggi dan $\mathrm{pH}$ yang rendah. Dampak yang ditimbulkan dari tingginya bahan organik pada effluent pabrik tahu menyebabkan gangguan terhadap kehidupan biotik dan turunnya kualitas air perairan. Pencemaran oleh limbah cair tahu juga menyebabkan kerusakan ekosistem perairan dan akan menyebabkan penurunan kesehatan kepada manusia (Adack, 2013).

Sistem wetland merupakan pilihan pengolahan yang baik untuk pengolahan limbah cair tahu, terutama untuk pabrik tahu berskala kecil. Tumbuhan juga menghasilkan bahan organik yang dapat meningkatan rasio biodegradable yang disebut eksudat (Mangkoedihardjo dan Samudro, 2010). Salah satu tumbuhan yang mampu mereduksi bahan organik adalah
Typha latifolia. Menurut Leto et al., (2013) Typha latifolia mampu mereduksi BOD sebesar 64.8\%. Selain itu Typha latifolia diketahui mampu menyerap pencemaran logam kromium pada tanah (Goudarzi dan Afrous, 2012). Oleh sebab itu, penelitian ini bertujuan untuk mengolah limbah organik yang berasal dari pabrik tahu supaya memenuhi ambang batas yang aman bagi lingkungan.

\section{METODOLOGI}

Penelitian dilaksanakan di Laboratorium Teknik Lingkungan, Universitas Nahdlatul Ulama Sidoarjo. Sampel diambil dari pabrik tahu yang berada di Desa Sepande, Kecamatan Sidoarjo. Lokasi pelaksanaan berdekatan dengan lokasi sampling sehingga mempermudah proses pengambilan limbah cair dan proses pelaksanaan penelitian. Data yang digunakan untuk menyusun penelitian ini berupa data primer. Data primer diperoleh dari hasil analisis laboratorium baik laboratorium internal maupun eksternal.

Bahan yang dibutuhkan dalam penelitian ini adalah limbah cair pabrik tahu yang dihasilkan dari Pabrik Tahu di daerah Sepande, Sidoarjo. Pengolahan limbah cair 
ISSN: 2528-4002 (media online)

ISSN: 2355-892X (print)

Online: http://e-journal.sari-mutiara.ac.id/index.php/KesehatanMasyarakat

DOI: https://doi.org/10.51544/jkmlh.v6i1.1562

pabrik tahu di daerah Sepande Sidoarjo masih belum efektif, sehingga limbah cair yang dihasilkan langsung dibuat ke badan air. Selain itu, dibutuhkan tanaman Typha latifolia dan media wetland berupa tanah, kerikil, dan pasir.

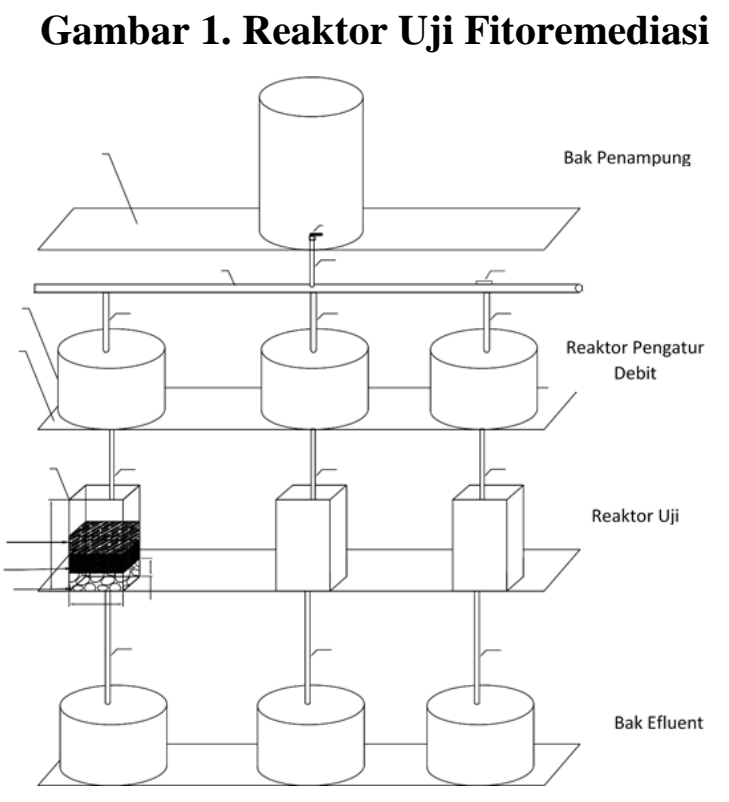

Sedangkan peralatan yang dibutuhkan dalam penelitian ini antara lain: reaktor miniplan skala laboratorium berupa: reactor contructed wetland, bak pengumpul, reaktor effluent, pipa dan kran, box sampel, dan botol sampel. Desain reaktor ditunjukkan pada gambar 1. Adapun waktu tinggal yang direncanakan adalah 2 jam dan debit yang direncanakan sebesar $15 \mathrm{~L} /$ hari.

Uji pendahuluan dilakukan dengan mengambil sampel sebanyak $1 \mathrm{~L}$ dari reaktor effluent pabrik tahu di daerah Sepande, Sidoarjo, lalu menganalisa kadar BOD dan COD di Laboratorium. Pada tahap aklimatisasi, tumbuhan Typha latifolia yang diambil dari wetland di sekitar Universitas Nahdlatul Ulama Sidoarjo diletakkan pada tangki selama 1 minggu. Selanjutnya tumbuhan disiram setiap hari menggunakan air kran. Kemudian tumbuhan Typha latifolia yang hidup setelah proses aklimatisasi akan digunakan untuk penelitian. Setelah dilakukan tahap aklimatisasi, selanjutnya dilakukan uji fitoremediasi selama satu minggu dengan variasi konsentrasi COD. Typha latifolia ditanam $10 \mathrm{~cm}$ dari permukaan media. Selanjutnya dilakukan analisa parameter setiap hari hingga 5 hari untuk mengetahui fluktuasi konsentasi BOD dan COD.

Parameter yang dianalisis pada penelitian ini yaitu BOD dan COD. Analisis parameter dilakukan setiap hari. Analisis BOD menggunakan metode Winkler. 
ISSN: 2528-4002 (media online)

ISSN: 2355-892X (print)

Online: http://e-journal.sari-mutiara.ac.id/index.php/KesehatanMasyarakat

DOI: https://doi.org/10.51544/jkmlh.v6i1.1562

Sedangkan analisis COD menggunakan metode Refluks. Data yang diperoleh akan disajikan dalam bentuk tabel dan grafik. Kemudian dilakukan pembahasan dengan mengevaluasi, menguraikan, dan menyelidiki hasil yang telah diperoleh dengan membandingkan penelitian terdahulu.

\section{HASIL}

Penelitian telah selesai dilaksanakan dan berhasil didapatkan hasil bahwa berupa nilai parameter BOD dan COD menggunakan reaktor Constructed wetland dengan variasi jumlah tumbuhan Thypa latifolia (sebanyak 2 batang dan 3 batang) dan variasi media menggunakan media filter berupa pasir dan tanah liat. Hasil effluent yang didapatkan dari parameter BOD yaitu nilai parameter BOD tanpa media dari waktu detensi $1-4$ hari berturut-turut adalah 13\%, $34 \%$, 49\%, dan 53\% seperti pada gambar 2 . Kemudian nilai parameter BOD dengan media pasir dan 2 batang tumbuhan Thypa latifolia menunjukkan efisiensi sebesar $16 \%$, $20 \%, 22 \%$, dan 46\%. Sedangkan untuk media pasir dengan variasi jumlah tumbuhan Thypa latifolia sebanyak 3 batang berturutturut adalah 18\%, 32\%, 46\%, dan 52\%. Pada media tanah dengan jumlah tumbuhan Thypa latifolia sebanyak 2 batang menunjukkan efisiensi pengurangan BOD dengan waktu detensi $1-4$ hari berturut-turut adalah $34 \%$, 46\%, 56\%, dan 65\%. Sedangkan untuk variasi jumlah tumbuhan Thypa latifolia sebanyak 3 batang menunjukkan efisiensi pengurangan BOD sebesar 36\%, 60\%, 61\%, dan $72 \%$.

\section{Gambar 2. Persentase Efisiensi} Penyisihan BOD

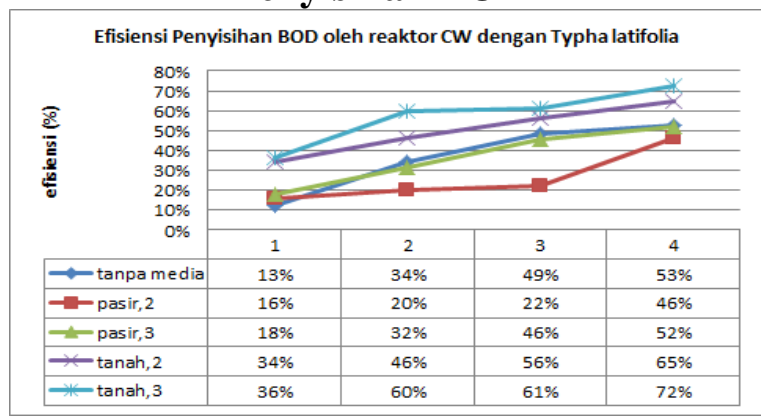

Hasil effluent yang didapatkan dari parameter COD yaitu nilai parameter COD tanpa media dari waktu detensi $1-4$ hari berturut-turut adalah 13\%, 34\%, 36\%, dan $61 \%$ seperti gambar 3. Kemudian nilai parameter COD dengan media pasir dan 2 batang tumbuhan Thypa latifolia menunjukkan efisiensi sebesar 16\%, 27\%, $38 \%$, dan 59\%. Sedangkan untuk media pasir dengan variasi jumlah tumbuhan Thypa latifolia sebanyak 3 batang berturut-turut adalah 27\%, 47\%, 52\%, dan 64\%. Pada 
ISSN: 2528-4002 (media online)

ISSN: 2355-892X (print)

Online: http://e-journal.sari-mutiara.ac.id/index.php/KesehatanMasyarakat

DOI: https://doi.org/10.51544/jkmlh.v6i1.1562

media tanah dengan jumlah tumbuhan Thypa latifolia sebanyak 2 batang menunjukkan efisiensi pengurangan COD dengan waktu detensi $1-4$ hari berturut-turut adalah $32 \%$, $52 \%, 74 \%$, dan $84 \%$. Sedangkan untuk variasi jumlah tumbuhan Thypa latifolia sebanyak 3 batang menunjukkan efisiensi pengurangan COD sebesar 35\%, 47\%, 59\%, dan $65 \%$.

\section{PEMBAHASAN}

Limbah tahu adalah limbah yang dihasilkan dalam proses pembuatan tahu, proses pencucian kedelai dan pencucian peralatan produksi. Limbah pabrik tahu yang dihasilkan berupa slimbah padat dan cair. Limbah tersebut mengandung bahan organik, bila langsung dibuang kebadan air tanpa adanya proses pengolahan maka akan menyebabkan pencemaran air. Pencemaran yang dilakukan terus menerus akan mengakibatkan kematian organisme perairan, hal itu disesbkan perubahan kondisinya menjadi anaerob.

Upaya pengolahan limbah cair pabrik tahu secara umum telah dikembangkan diantara metode fisika, kimia maupun biologi. Pengolahan limbah secara fisika bisa dilakukan dengan filtrasi dan sedimentasi. Sedangkan pengolahan secara kimia dapat dilakukan dengan kogulasi dan flokulasi. Baik pengolahan fisika maupun kimia membutuhkan biaya yang lebih besar dibanding pengolahan secara biologi. Pengolahan biologi bisa dilakukan dengan tumbuhan sebagai agen remediasi. Dalam hal ini mengggunakan tuumbuhan Thypa latifolia.

\section{Gambar 3. Persentase Efisiensi}

Penyisihan COD

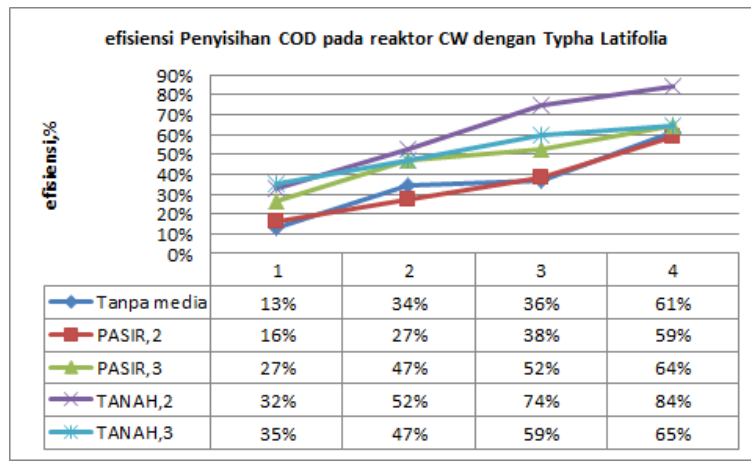

Tumbuhan Thypa latifolia merupakan tumbuhan perenial yang tingginya mampu mencapai 2.5 - 3 meter. Perkembangbiakannya dibantu dengan angin, karena bunga yang dihasilkan bersifat monoecious. Tumbuhan ini memiliki batang yang tumbuh di dalam tanah atau yang disebut rizome. Berdasarkan penelitian Guedeset al. (2009) Typha latifolia mampu mendegradasi pencemaran protelium pada 
ISSN: 2528-4002 (media online)

ISSN: 2355-892X (print)

Online: http://e-journal.sari-mutiara.ac.id/index.php/KesehatanMasyarakat

DOI: https://doi.org/10.51544/jkmlh.v6i1.1562

tanah. Selain mampu mendegradasi protelium, Typha latifolia mampu menurunkan konsentrasi COD, BOD, dan TSS masing-masing sebesar $50.15 \%$, $56.72 \%$, dan $88.83 \%$ pada limbah domestik (Andriani et al., 2012). Menurut Elystia (2014) Typha latifolia dengan densitas 1 $\mathrm{g} / \mathrm{cm}^{2}$ mampu menurunkan konsentrasi BOD 97.33\% dengan residence time 9 hari pada limbah cair kelapa sawit.

Pengolahan limbah induustri tahu dapat dilakukan menggunakan sistem wetland buatan (contructed wetland system). Contructed wetland terdiri dari satu atau lebih sel pengolahan pada reaktornya dan dipengaruhi oleh model rancangan. Contructed wetland telah digunakan untuk mengolah banyak jenis limbah cair. Wetland dibedakan menjadi 2 jenis, yaitu Subsurface Flow (SSF) dan Free Surface Flow (FSF). SSF dirancang dengan membuat aliran subpermukaan. FSF dirancang untuk meningkatkan kinerja wetland alami dengan mengalirkan air limbah yang diatas permukaan tanah pada ke dalaman yang dangkal. FSF cocok digunakan untuk daerah yang bertemperatur tinggi seperti Arab Saudi (Sheikh, 2006). Secara umum wetland dirancang untuk menghilangkan lebih dari 90\% BOD, COD, SS, dan bakteri yang ada di air limbah. Wetland juga mampu menghilangkan $\mathrm{N}$ dan $\mathrm{P}$ hingga $50 \%$ (Wassen et al., 1998). Selain kontaminan organik, wetland juga mampu menghilangkan kontaminan anorganik, seperti logam berat (Chen et al., 2009).

Wetland yang digunakan dalam penelitian ini mengandung media kerikil, pasir, batu kecil yang ditumbuhi tumbuhan air. Pasir adalah media wetland yang penting karena mampu memfilter partikel kecil yang melewati lapisan kerikil. Lapisan pasir juga mampu menahan bakteri dan mikroorganisme lainnya yang terkandung pada limbah. Selain itu, pasir membantu menghalangi timbulnya nyamuk (Nguyen, 2020). Menurut Białowiec al. (2013), menyatakan bahwa campuran pasir atau kerikil mampu meningkatkan penyerapan phosphor pada wetland. Oleh karena itu, komposisi media menentukan besar penyisihan (Sirianuntapiboon et al., 2006). Sebagaimana hasil penelitian ini, terdapat peningkatan efisiensi penghilangan BOD dan COD pada waktu detensi 1 hari dibandingkan dengan tanpa media pasir. 
ISSN: 2355-892X (print)

Online: http://e-journal.sari-mutiara.ac.id/index.php/KesehatanMasyarakat

DOI: https://doi.org/10.51544/jkmlh.v6i1.1562

Penelitian ini menunjukkan bahwa penggunaan media tanah memberikan hasil yang lebih baik dibandingkan dengan media pasir. Kenyataan di lapangan media tanah mampu menyerap bau asam dari air limbah tahu. Sistem yang digunakan dalam penelitian adalah sistem batch dengan debit 10 Liter/hari dan waktu tinggal 24 jam.

Variasi jumlah tumbuhan Thypa latifolia juga menentukan kemampuan untuk menghilangkan kandungan BOD dan COD pada limbah industria tahu. Dari hasil penelitian diketahui bahwa efisiensi penghilangan BOD tertinggi menggunakan media tanah dengan jumlah tumbuhan Thypa latifolia 3 batang dan waktu detensi 4 hari sebesar $72 \%$. Hal ini menunjukkan bahwa semakin banyak tanaman akan semakin meningkatkan efisiensi dalam reaktor constructed wetland. Sedangkan bahwa efisiensi penghilangan COD tertinggi menggunakan media tanah dengan jumlah tumbuhan Thypa latifolia 2 batang dan waktu detensi 4 hari sebesar $84 \%$. Hal ini menunjukkan bahwa media tanah liat lebih efisien dalam menyaring dan menyisihkan kadar pencemar organik berupa COD dalam air limbah industri tahu. Sedangkan pengaruh $\mathrm{pH}$ dan suhu pada pengolahan cukup signifikan dimana limbah cair tahu kedelai lebih bersifat asam pada suhu di atas $30^{\circ} \mathrm{C}$. Hal ini mengingat pada proses pengolahannya menggunakan bahan baku cuka untuk mengawetkan dan proses pendidihan sehingga air limbah yang dihasilkan cenderung bereaksi panas sebagai bentuk pelepasan energi eksoterm. Berdasarkan hasil penelitian diketahui bahwa baik pada jumlah tanaman dengan 2 batang atau 3 batang terjadi efisiensi penurunan parameter kimia yang tidak begitu berbeda. Namun dapat dijelaskan bahwa pada keempat reaktor dari hari pertama sampai keempat penelitian, efisiensi penurunan parameter kimia semakin meningkat.

\section{KESIMPULAN}

Berdasarkan hasil dan pembahasan dapat disimpulkan bahwa terjadi penurunan kadar BOD dan COD pada limbah cair industri tahu di Sidoarjo dengan menggunakan Sistem Constructed Wetland. Adapun persentase penurunan kadar BOD terbesar pada media tanah dengan jumlah tumbuhan Thypa latifolia 3 batang dan waktu detensi 4 hari sebesar $72 \%$. 
ISSN: 2528-4002 (media online)

ISSN: 2355-892X (print)

Online: http://e-journal.sari-mutiara.ac.id/index.php/KesehatanMasyarakat

DOI: https://doi.org/10.51544/jkmlh.v6i1.1562

Sedangkan persentase penurunan kadar COD terbesar pada media tanah dengan jumlah tumbuhan Thypa latifolia 2 batang dan waktu detensi 4 hari sebesar $84 \%$.

\section{REFERENSI}

Adack, Jessy. Dampak pencemaran limbah pabrik tahu terhadap lingkungan hidup. Lex Administratum 1.3 (2013).

Andriani, R., and Y. Fajriana. Removal of municipal wastewater BOD, COD, and TSS by phyto-reduction: A laboratoryscale comparison of aquatic plants at different species Typha latifolia and Saccharum spontaneum. International Journal of Engineering and Innovative Technology 2 (2012): 333 citation_lastpage.

Białowiec, Andrzej, Antonio Albuquerque, and Peter F. Randerson. The influence of evapotranspiration on vertical flow subsurface constructed wetland performance. Ecological Engineering 67 (2014): 89-94.

Elystia, Shinta. Pengolahan Kandungan COD Limbah Cair Pabrik Kelapa Sawit oleh Typha Latifolia dengan Metode Fitoremediasi. Jurnal Dampak 11.2 (2014): 88-95.
Goudarzi, Shahram, and Ali Afrous. Phytoremediation of the Sludge Contaminated with Chromium by Aquatic Plants in Dezful. Bulletin of Environment, Pharmacology and Life Sciences 1.9 (2012): 58-60.

Guedes, C. L. B., et al. Evaluate the Typha latifolia remediation potential in petroleum contaminated soil: monitoring crude oil aromatic fraction and nutrient absorption by plant. Proceedings of the 11th international conference on Environmental Science And Technology, Chania, Crete, Greece. 2009.

Leto, Claudio, et al. Effects of plant species in a horizontal subsurface flow constructed wetland-phytoremediation of treated urban wastewater with Cyperus alternifolius L. and Typha latifolia L. in the West of Sicily (Italy). Ecological engineering 61 (2013): 282-291.

Mangkoedihardjo, S. dan Samudro, G. 2010. Fitoteknologi Terapan. Graha Ilmu, Yogyakarta.

Mengzhi, Chen, et al. Study on the heavy metals removal efficiencies of 
ISSN: 2528-4002 (media online)

ISSN: 2355-892X (print)

Online: http://e-journal.sari-mutiara.ac.id/index.php/KesehatanMasyarakat

DOI: https://doi.org/10.51544/jkmlh.v6i1.1562

constructed wetlands with different substrates. Journal of water Resource and Protection 2009 (2009).

Nguyen, X. Cuong, et al. Combined biochar vertical flow and free-water surface constructed wetland system for dormitory sewage treatment and reuse. Science of The Total Environment 713 (2020): 136404.

Sheikh, Bahman. Use of Constructed Wetlands for Wastewater Treatment and Water Recycling-Application to Saudi Arabian Conditions. Water Reuse Consultant, San Francisco, California. USA (2011).

Sirianuntapiboon, Suntud, Manoch Kongchum, and Worawut
Jitmaikasem. Effects of hydraulic retention time and media of constructed wetland for treatment of domestic wastewater. African Journal of Agricultural Research 1.2 (2006): 027-037.

Sugianti, Mifta, and S. T. M. Rois Fathoni. Kajian Pengolahan Limbah Padat dan Limbah Cair Pabrik Tahu di Semarang, Jawa Tengah. Diss. Universitas Muhammadiyah Surakarta, 2019.

Wassen, Martin J., Roland E. van der Vliet, and Jos TA Verhoeven. Nutrient limitation in the Biebrza fens and floodplain (Poland). Acta Botanica Neerlandica 47.2 (1998): 241-253. 